\title{
Energy efficient environment in architecture
}

\author{
Samuratova Tatigul Kakenovna ${ }^{1,{ }^{*}}$, Kaliyeva Zhanar Eralinovna ${ }^{1}$, Mukhtar Makhanov ${ }^{1}$, \\ and Yermekova Zhadyra Kerymbaevna ${ }^{1}$
}

${ }^{1}$ L. N. Gumilyov Eurasian National University. Nur-Sultan, Kazakhstan

\begin{abstract}
In modern conditions the building can not only consume energy from the outside, but also produce its own. A new role has acquired such energy sources as the sun and wind. Energy saving in architecture follows from the requirements of regulatory documents and includes: the use of alternative energy sources, the installation of energy-saving equipment. Using examples of modern technologies, it is shown that along with energy savings, it is possible to create environmentally friendly and more interesting architectural images. The basics of the formation in the architecture of energy-efficient spaces, methods and techniques of using the energy of the future in the architecture of Kazakhstan are studied.
\end{abstract}

\section{Introduction}

In the XXI century, the development of architecture is rapidly increasing, the design of tall buildings, the compaction of urban buildings, where architects need to take into account the construction of these buildings on the natural environment and the safety of residents. Architecture is an integral part and urban human life and has an impact on the psyche and health of people. But not only architecture determines the way of life of a person, but also the way of life of a person determines certain features of buildings. Architecture defines the world view in space. The perception of the environment is deeply subjective. Among architects and builders at the present time one of the most pressing topics is the topic of environmental protection, healthy lifestyle and the creation of environmentally friendly housing.

The easiest way to reduce the degree of environmental pollution is energy saving, i.e. more rational use of energy. The environment is associated with architecture. Each country has an original architectural environment. Kazakhstan is distinguished by its original national architecture. It reflects the national identity of the people and create new styles that rely on the culture of the Great Steppe. Also supports the relationship between the national and international architectural base.

A modern architectural base requires the solution of many problems of the formation of modern buildings, which must meet the requirements of energy efficiency and economy. In this connection, construction should have a prospect that harmoniously blends into the natural

\footnotetext{
*Corresponding author: samyratovatk@mail.ru
} 
environment, which is confirmed by the Law of the Republic of Kazakhstan "On Energy Saving and Improving Energy Efficiency." (Law of the Republic of Kazakhstan) [1].

\section{Methods}

To hold a discussion on the following issues: - energy saving is the task of a sustainable architecture; - a combination of architectural and engineering solutions; - The principles of the formation of an energy-efficient spatial environment; - a combination of natural environment and artificial structures [2].

Today, the concept in the architecture of an energy-efficient spatial environment is no longer new. The discussion about energy conservation as a method of environmental protection is conducted at the beginning of the last century, at the same time there was a theory addressing these issues, but now this topic has attracted the attention of almost all scientists. Architects and engineers emphasize that environmental protection is sustainable, incorporating the latest technological developments in energy efficiency, intelligent building management, the use of spatial and architectural methods, the maximum use of natural, not mechanical, engineering systems" [3].

Some scientists consider architecture designed on the principles of sustainable development to be called sustainable, "green", eco-sustainable, eco-friendly, energy-efficient and other terms. Scientists who share this view point to the energy-efficient space of many cities were limited only to greening and reducing industrial emissions to the environment.

Scientist D.O. Shvidkovsky sees the task of sustainable architecture in creating such a habitat that is necessary for the present generation, but it will also satisfy the future generation. Y.A. Tabunshchikov calls sustainable architecture a combination of architectural and engineering solutions that will favorably influence the natural environment and human life, as well as maintain ecological balance [4].

In the study, the author used theoretical methods: the study of special literatures; observation, analysis and synthesis. Collecting information on the topic of research from the works of scientists. Given the concept of the development of sustainable architecture, the inclusion in the architecture of the latest technological developments in energy efficiency, the basic principles of energy-efficient architecture, the principles of influence on people, and the "talking architecture".

\section{Energy-efficient spaces}

Today, the concept of energy-efficient spatial environments in architecture is no longer new. There was a theory that considered these issues. It has been limited to greening and reducing industrial emissions to the environment.

D. Shvidkovsky sees the task of sustainable architecture in creating such a habitat, which is necessary for the present generation, but will also be satisfied by the future generation. Tabunshchikov calls sustainable architecture a combination of architectural and engineering solutions that will favorably influence the natural environment and human life, as well as maintain ecological balance [4].

In a scientific study "Green Design of Residential High Rise Buildings in Livable Cities" (Green design of high-rise residential buildings in metropolitan areas) Mir M. Ali (PhD) and Paul J. Armstrong (RA), presented at the IBS/NAHB Symposium (Orlando, Florida in 2008), states that high-quality living environment is associated with the design, integration of sustainable principles applicable to high-rise residential buildings in an urban environment. They propose to use high-performance technologies to improve the energy efficiency of 
buildings, use solar photovoltaic panels, wind turbines, fuel cells and a passive design to complement the convection of heating and cooling systems. The work positively assesses the design experience in which the architectural and planning characteristics of the building are aimed at the qualitative use of passive solar energy, the creation of natural ventilation and the most efficient use of daylight. It is proposed to introduce vertical gardening and the creation of landscape spaces inside the objects to improve indoor air quality and control the microclimate [5].

The basic principles of the architecture of energy-efficient high-rise residential buildings should include: aesthetics of the environment as a whole (building, landscape, community, etc.); economic efficiency (affecting not only the construction process, but also operation); potential operational functionality in the context of time (to anticipate changes in information technologies and other building systems); performance and health (design of the living environment as a single system of a "healthy home" - the absence of excessive noise, drafts, thermal and humidity characteristics; safety (electrical safety, ergonomics, accident prevention, etc.) (International competition of architecture).

These principles all influence the formation of an energy-efficient spatial environment per person. The following methods can be distinguished: the relationship between the architectural environment and the person, the building and the environment; communication of the building and space with the scale and needs of the person; aesthetic and emotional features of the formation and perception of the architectural and spatial environment; psychological features of architectural means and methods of forming the architectural and spatial environment [6]. The architectural and spatial environment can affect a person due to certain mechanisms, the so-called "incentives" [7].

\section{Energy of future in Nur-Sultan's architecture}

In the Middle Ages, the crystal ball symbolized omniscience. Alchemists tried to create a philosopher's stone - it had to be a perfect round shape and have magical powers. Modern magic in the building of the Sphere is also guaranteed: it is an energy miracle, because it provides itself with energy [8]. In the perfect shape of the ball, the "hollow" is sharply striking. It was intentional. There was added a recess in which the wind begins its movement and passes through the tunnel to the two electric generators. A solar energy collector is built into the southern glass facade, and it is also planned to develop the heat of the earth thanks to heat pumps. In addition, the Sphere is also smart! It is equipped with a so-called SMART system that calculates energy consumption exactly according to the number of people inside [9].

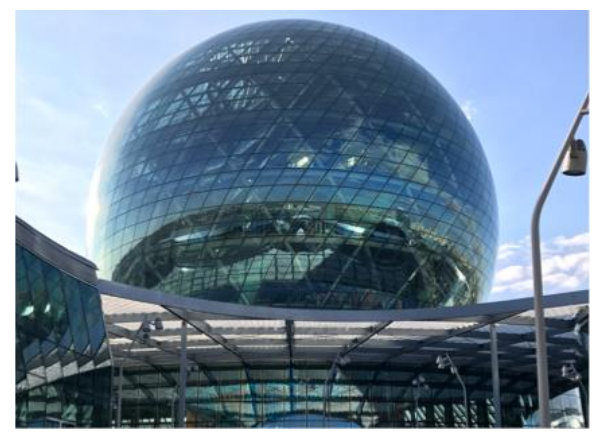

Fig. 1. Symbol of EXPO-2017. The author: Albert Speer Jr., 2017, photo by G. Akhmetova.

The main object of the EXPO-2017 exhibition is the Nur Alem building. Here the concentration of technological innovation has reached a peak. During the construction of the 
sphere, high-tech double-layer glass was used, which isolates the space from external temperature and sound. Photovoltaic elements that convert solar energy into electrical energy are integrated into the design of the Nur Alem facade. In the upper part of the sphere there are two wind turbines, they draw wind energy into electricity. If the shell of the sphere demonstrates the progress of the present, then the technologies of the future are concentrated in the heart of the sphere - something that can save the planet in the coming years [10].

This pavilion includes the Museum of Energy of the Future. It occupies 8 floors, each of which reflects its concept: "Future Astana", "Energy of Space", "Energy of the Sun", "Energy of the Wind", "Energy of Biomass", "Kinetic Energy", "Energy of Water" and "National Pavilion" located at the base of the sphere. According to the authors, about $80 \%$ of the energy consumed in the future should be obtained using green technology. On the seventh floor, uncharted expanses of space are revealed and will reveal the full potential of cosmic energy and a solar tree, a thermonuclear reaction simulator and a gallery of solar mobility. The sixth museum of wind and air, which describes the causes of the tornado and the impact of air flow on the meteorological conditions of the area. The fourth floor is about biomass energy. An interactive laboratory is located on a large area, where anyone can make interesting experiments. The third floor of the ball, dedicated to kinetic energy, will be a fun attraction for children and teenagers. Here are located exercise bikes, having turned around which to produce energy, cars that start from movement. On the second floor with the energy of water. Here are water mills, the first communicating vessels, fountains and aqueducts. The first floor of 5000 square meters is reserved for the national pavilion and tried to accommodate the country's history, traditions and culture of Kazakhstan, the development of scientists in the field of alternative energy. "Nur Alem" in Astana has already become a new symbol of Kazakhstan and is rightfully a museum of the future [11].

One of the leading buildings of Nur-Sultan with zero energy is the eco-mosque "Allanyn Guli". The building is made in the style of postmodernism, using traditional ornaments and decorative elements. The main building has a complex, hemispherical shape, consisting of triangular inclined planes, culminating in a dome, whose diameter is 26 meters. Externally, the design of the mosque resembles a flower and at the same time a diamond face. The height of the minaret, located on the north side of the main building of the mosque, is 43.5 meters, and it is made in the form of a kalam, a sacred feather. The alternative sources used to power the new mosque produce three times the amount of electricity from the required volume. The area of the mosque building is more than 2.2 thousand square meters. This is the ninth in the city of Nur-Sultan, the only mosque in the world, the level of energy consumed is zero. This is done by solar panel. In fig. $2(\mathrm{a}, \mathrm{b})$ - a modern building on top resembles a huge geometric flower. After all, it was not for nothing that the name "Allanyn Guli" was chosen [12].

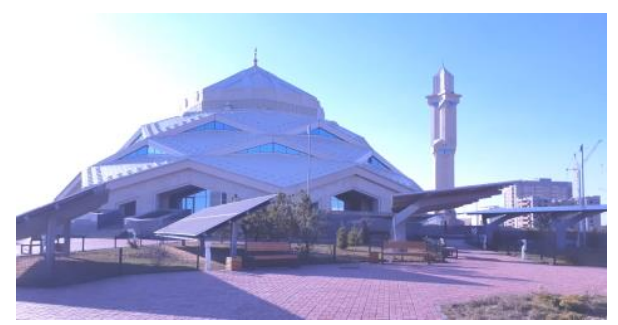

a

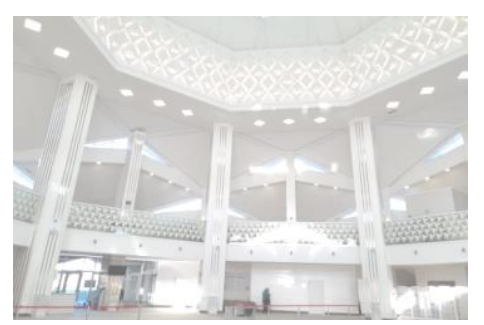

b

Fig. 2. (a, b) Mosque "Allanyn Guli". The author - Dzhambulatov S., 2018, photo - Samuratova T.K.

Executed in the style of postmodernism, the structure is laconic and restrained in everything. In fig. 2 (a, b) - snow-white interior decoration, a minimum of ornaments and 
decorative elements are shown. The mosque with its unusual design is already very popular among the citizens.

The architect of the unusual structure is Sagyndyk Zhanbolatov, who previously designed the largest mosque in Central Asia "Hazrat-Sultan. The main designer of the building was the company Neubau best energy. Neue Bauphysik \& Energiedesign GmbH and Weissenseer were partners in the construction of the Ryskeldi kazy mosque. Today, they are leaders in the development of eco-objects.

This project is a special example of an energy-saving facility, the main point is to reduce energy costs. To insulate a building well, it is necessary to isolate it. For example, the insulation of all window structures, ventilation structures - all this must be isolated and sealed, in order to have the lowest heat loss.

According to experts, the construction of the object was based on three-dimensional models. Insulating structures were used by $20-25$ percent more than at other objects. Indoors 4-chamber glazing of windows, which led to the fact that there was a decrease to 60 percent in need of heating. A monitoring system is held in the mosque, where heat, heating and temperature monitoring are carried out.

During the construction photovoltaic panels and energy roofs with solar panels were used (Fig. $3(a, b)$ ). They are installed on the south side, on the canopies of the parking and pedestrian areas.

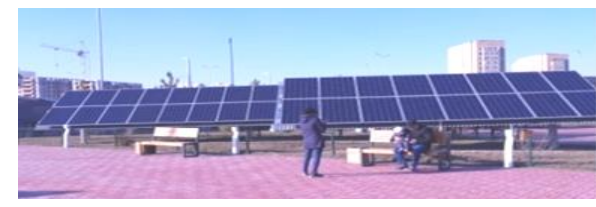

a

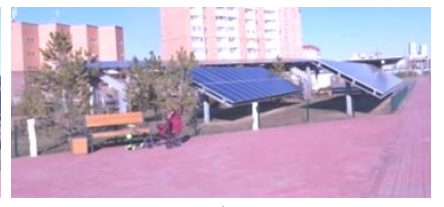

b

Fig. 3. Energy roofs with solar panels. The author - Dzhambulatov S., 2018, photo - Samuratova T.K.

To build an object under such climatic conditions for a European company was new. Because, with very cold frosts, such energy conservation of heat is a rather complicated undertaking.

Energy of the future: new construction technologies. The structures erected at the EXPO site represent a concentration of comfortable design and technological developments. The first calculations show that the technologies used make it possible to achieve $48 \%$ energy savings compared to conventional buildings. The amount of energy consumed is calculated according to the number of people in the room and the energy consumption of the processes performed by them. Such parameters as illumination, air conditioning systems, active power supply are calculated strictly according to the required quantity.

It can also be called the energy efficient building of the Khan's Tent shopping and entertainment center which makes up a single ensemble with the Palace of Peace and Accord. It is a unique combination of progressive technologies and bright national solutions. The height of the complex reaches 200 meters. This is one of the main attractions of the city and country. The impressive structure has the form of a giant tent made of fine mesh, which is covered with innovative material - fluoropolymer ETFE. It transmits light, but it effectively protects the building from cold and heat. Inside the tent there is a comfortable temperature that allows you to walk on it at any time of the year (Fig. 4, 5). 


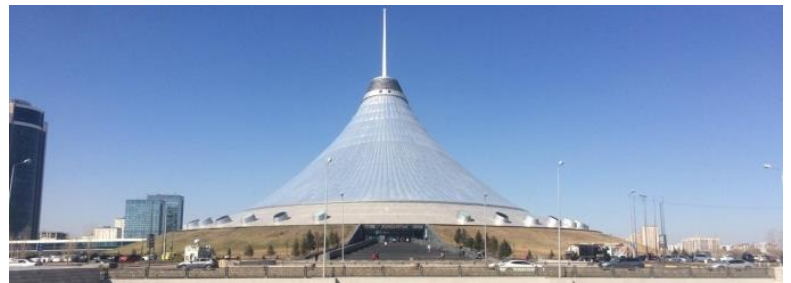

Fig. 4. The SEC «Khan's Tent». The author: Norman Foster, 2010, photo by Samuratova T.K.

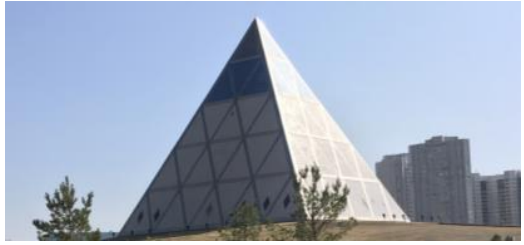

Fig. 5. Palace of Peace and Reconciliation. The author: Norman Foster, 2006, photo by Samuratova T.K.

\section{Conclusions and discussions}

In order to determine the satisfaction of various groups of people with the energy efficiency of the environment in the Nur-Sultan architecture, the city's urban development estimates in the area of improvement were studied.

The younger and older generation of the city of Nur-Sultan feels positive changes in the city for energy efficiency in architecture. Evaluating the improvement of the city of NurSultan, the respondents expressed the following opinions: $80 \%$ of respondents rate the improvement of Nursultan as good, 17\% - satisfactory, 3\% - unsatisfactory. The city acts as a formative factor in the living space in which human activity takes place.

As a result of the study, it should be noted that for the residents of the city of Nur-Sultan it is very important to see the results of works on the improvement and greening of the city. Preservation and improvement of the environment surrounding a person in the city, creation of conditions in the city that have a beneficial effect on the psychophysical state of a person, is a very important for Republic of Kazakhstan. Based on the study of the concept in the works, it was concluded that architecture is obliged to educate and educate people. Having studied the architecture of Nur-Sultan, it was proved that the architecture is equipped with the most modern alternative sources of energy and energy efficiency. Round forms in architecture provide energy, the use of photovoltaic panels and energy roofs with solar panels, a tent made of fine mesh, fluoropolymer etfe. passes light, but at the same time effectively protects the building from non-weather motives.

The modern architecture of Astana is a bizarre, but at the same time harmonious combination of Eastern traditions and bold architectural ideas of the West.

\section{References}

1. Law of the Republic of Kazakhstan dated January 13, 2012 No. 541-IV "On Energy Saving and Improving Energy Efficiency" (with changes and additions as of January 15, 2019)

2. http://zvt.abok.ru/articles/255/ustoichivaya_arhitektura__vzglyad_inzhenera 
3. A. N. Remizov, Development Strategy for Sustainable Architecture in Russia (Sustainable Architecture: Present and Future, Proceedings of the international symposium, November 17-18, 2011)

4. Assessment of the sustainability of student projects in the educational process of the Moscow Architectural Institute (State Academy). Webinar of marches - avoc, May 20, 2015, http://webinar.abok.ru / webinar / marhi-2015

5. S. A. Molodkin, The principles of the architecture of energy-efficient high-rise residential buildings (Thesis for the degree of Candidate. arch., 2007)

6. V. V. Shilin, Architecture and psychology. brief lecture notes (Publishing house Nizhegorod. state archit.-builds. University, 2011)

7. V. Andreeva, Encyclopedia. symbols, signs, emblems (2004)

8. Talking architecture [Electron. resource] / Cultnou. Culture and art of Russia and the world. - Access mode: http://www.cultnow.ru/hooms-440-1.html, (appeal date: 03/27/2017).

9. Yu. M. Semiosphere, Yu. M. Lotman (2000)

10. https://khabar.kz/ru/dostoprimechatelnosti/item/105539-sfera-nur-alem

11. https://archspeech.com/expo-astana/sfera-v-astane-ob-ekt-kotoryy-stanet-simvolovgosudarstva

12. Z. Tukpiev, The mosque with zero energy consumption opened in Astana (2018) 